\title{
ESTERILIDADE FEMININA
}

\author{
Prof. MORAES BARROS (1)
}

O tema a ser debatido, já pelo seu alto signifíicado médico-social, já pela variedade e complexidade dos problemas-que suscita, já pelo interesse prático que lhe é peculiar, mantêm-se de permanencia na ordem do dia e ocupa largo espaço na patologia genital. Os livros dedicam-lhe extensos capítulos, nas revistas e associações científicas ele aparece, frequentemente, na tela da discussão, alimentando controversias e promovendo conflito de opiniões.

$E^{\prime}$ frequente sermos procurados por casais que não têm filhos e que desejam tê-los. E essa aspiração à prole, que é instintiva na espécie humana, se apresenta, na mulher, por vezes, tão exaltada e imperativa, que ela perambula pelos consultórios, a tudo recorre e a tudo se submete, para se curar dessa inferioridade fisiológica. E a cura da esterilidade é problema clínico dos mais sugestivos que possa defrontar o especialista, dos que mais põem à prova o seu saber, sagacidade e experiência. Si a reprodução é o objetivo máximo da biologia feminina, si na hierarquia das funções que integram a economia da mulher, é a mais graduada, fundamental é o preceito de a instalar ou restabelecer, quando ausente, assim como indeclinavel é o dever do ginecolơgista de zelar por sua preservação.

$\mathrm{O}$ assunto é vasto e complexo. $\mathrm{Na}$ impossibilidade de explaná-lo em detalhe e com o desinvolvimento que fôra para desejar, eu me limitarei a estudá-lo em suas linhas gerais, focalisando os seus aspectos mais interessantes, expondo-os à luz dos mais recentes conhecimentos, condensando e resumindo a materia, como o exige a premencia do tempo.

Esterilidade é a incapacidade para conceber. Si essa incapacidade não é para conceber, mas para conduzir a prenhez até o nascimento de feto vivo e viavel, dá-se o nome de infertilidade. Si tão simples é o conceito biológico da esterilidade, já o é menos o seu conceito clínico, porissó que a aptidão para conceber varía de indivíduo a indivíduo. Entre três mulheres, em condições mais ou menos idênticas, enquanto uma concebe anualmente, a segunda o faz cada 2 anos, e a terceira, cada três ou quatro. E são tỏdas fecundas. $\mathrm{Na}$ mesma mulher, a capacidade para procrear, varia e se condiciona a influências de clima, de alimentação, de profissão, etc.

(1) Aula dada em agoste - 1941. 
Consideremos, de início, as diversas modalidades sob as quais se apresenta a esterilidade. Tais são:

1) esterilidade primitiva ou secundária (unigena);

2) esterilidade absoluta ou relativa;

3) esterilidade natural ou artificial (terapêutica ou voluntária);

4) esterilidade humoral e hormônica;

5) esterilidade fisiológica.

Primitiva é a da mulher que nunca concebeu. Secundária, daquela que já teve filhos e na qual a incapacidade se instalou secundariamente. Nesta há a considerar a esterilidade de um só filho - one child sterility, dos ingleses - que sucedeu a uma única prenhez, em géral condicionada por uma complicação puerperal.

Absoluta é a esterilidade que'se prende a uma condição local permanente que impede, irremissivelmente, a concepção. Relativa, quando essa condição local póde promover, mas não promove, necessariamente, a incapacidade.

Natural ou artificial - são expressões, por si sós, suficientemente claras, sendo que a artificial, ou foi instalada com fins terapêuticos, ou procurada pela mulher, ela próprià, por não desejar mais filhos. E' a modalidade que responde pelo maior número de casos, que diz com o uso dos incontáveis recursos anti-concepcionais, ineficientes na sua maior parte, prejudiciais quasi todos.

Humoral é a que se obtem pela administração, por via parenteral de determinadas substâncias que atuam como antígenos - esperma de carneiro - provocando a formação de anticorpos que tornam o meio humoral do indivíduo, hostil ao espermatozoide durante certo prazo. Hormonica é a que resulta de uma forte luteinisação do ovário e consequente suspensão das ovulações, quer se instale expontaneamente, como nos casos de cistos luteínicos, quer seja promovida artificialmente pela administração, em doses elevadas, de hormonios pre-hipofisários ou estrogênicos que acarretam aquela luteinisação.

Fisiológica, finalmente, é a esterilidade que, no conceito de Ogino-Knaus, existe efetiva e normalmente durante o decurso do ciclo menstrual, exceção feita dos poucos dias que circundam a ovulação. Opinam esses autores que o óvulo sobrevive limitado número de horas, em condições de ser fecundado, depois que abandona o folículo, contingência que, tambem, prevalece para o espermatozoide e que, consequentemente, só o coito realisado nos poucos dias que rodeiam a ovulação - tres dias antes e tres dias depois - póde conduzir à fecundação. Ora, sabido que a ovulação ocorre, mais ou menos, no meio do intermenstruo, consoante noção fisiológica bem assente, é nessa oportunidade que a fecundação terá lugar. Fóra desses poucos dias, a mulher é necessariamente esteril. Essa doutrina, esposada por uns e combatida por outros, mantem-se, ainda hoje, na tela da discussão, aguardando solução. De parte a parte se aduzem bons argumentos; e, enquanto o acordo não se estabelece, $\mathbf{x}$ noção prática a guardar é que, no decurso do ciclo menstrual, existe 
um periodo de fertilidade maior, mais propício à concepção e que deverá ser utilisado para o coito mais assiduo, pelos casais que desejam filhos, assim como para a abstinência, pelos que não os desejam. De muitas clientes me recordo eu que, fiéis observadoras da tabela KNaUs, como meio anti-concepcional, fracassaram no seu objetivo.

O problema clínico da esterilidade se desdobra em duas operações sucessivas: indagar e apurar a causa ou causas de uma esterilidade ocurrente, para, em seguida, intervir com o tratamento adequado a removê-la. Tanto equivale dizer - formular o diagnóstico e instituir a terapêutica.

Antes de abordarmos o assunto, nesse duplo aspecto, há vantagem em que fiquemos esclarecidos sobre as condições necessárias para que a fecundação se dê. Elas se repartem por três itens: $1^{\circ}$ ) que coexistam, num dado momento, no tracto genital feminino, óvulo e espermatozoides biologicamente sadios; 2. $)$ que subsista transito intra-genital, livre e desembaraçado; $3 .^{\circ}$ ) que sejam adequadas as condições estruturais do endométrio bem como as físico-químicas das secreções genitais. Quando ao $1^{\circ}$, compreende-se que o êxito da cundação em perspectiva, presupõe a boa saúde biológica das células que vão se conjugar, sem a qual ou fracassará o objetivo, ou, quando menos, faltarão ao ovo resultante, condições para se desenvolver. Quando à necessidade do livre trânsito intragenital, a condição é intuitiva. Si um obstáculo detiver o espermatozoide "na sua caminhada da vagina à trompa, ou o óvulo, do fólículo à mesma trompa, a esterilidade existirá. A $3 .^{a}$ condição é tão decisiva quanto as outras. Si o endométrio não se preparou devidamente, no decurso do ciclo menstrual, para receber e hospedar o ovo, este se desintegra e a prenhez fracassa, sem que qualquer sinal clínico denuncie a ocurrência. E o caso seria de infertilidade camouflada de esterilidade. Assim tambem, si a reação das secreções genitais, por sua excessiva acidez, for hostil à vida dos espermatozoides, eles sucumbirão à ação do meio e a mulher não conceberá. Toda e qualquer causa de esterilidade, pouco importa a sua origem ou natureza, terá que incidir, forçosamente, numa destas preliminares, afetando uma ou algumas delas e pondo-as em cheque.

Passemos ao estudo dessas causas. Inúmeras, sinão incontáveis, são as causas que condicionam, na mulher, a incapacidade procreadora. De. origem extra-genital, algumas, de séde genital, a maior parte. De um modo geral, póde-se afirmar que todas as doenças e disturbios da esfera genital, seja ela inflamatória, degenerativa, neoplasica, distópica ou funcional, em qualquer nivel em que se asseste, da vulva ao pelviperitoneo, póde dar causa a esterilidade.

E' claro que se me propuzesse a considerar discriminadamente, uma a uma, todas essas causas, teria que percorrer toda a patologia genital, o que é materialmente impossivel.. E nem isso é preciso. Basta que me limite às causas mais frequentes, mais encontradiças, que são as que oferecem maior interesse prático. Nesse objetivo, ex- 
cluam-se todas as causas de esterilidade relativa, de valor secundario, assim como a maior parte das causas de esterilidade secundaria. Nesta, a esterilidade se apresenta como sintoma de determinada moléstia genital, de cujo cortejo sintomático faz parte integrante. Reconhecida a doença pelos meios propedêtuticos usuais e removida que seja, pela terapêtutica, remove-se e cura-se a esterilidade que ela acarretara. Que se excluam tambem, as causas oriundas de.vícios congênitos atresias, imperfurações, etc. - que, além de raras, são de mediocre interesse clínico. Ocupemô-nos, de preferência, com as causas de esterilidade primitiva, ocurrente em mulheres que se casam e que convivem, sexualmente, durante periodo mais ou menos longo, sem conceber. São esses os casos que defrontamos, a miude, no consultório, neles se enquadra a quasi totalidade das clientes que nos procuram.

Essas causas se repartem em uterinas, tubárias e ovarianas. No útero, a condição patológica que, mais frequentemente, responde pela esterilidade é a hipoplasia, expressão que significa crescimento deficiente, desenvolvimento sub-normal do órgão. O útero não acompanhou o resto do organismo ou dos caracteres sexuais, na sua ev đluçấo formadora. Estacionou antes do tempo, em fase mais ou menos prematura. $E^{\prime}$ a condição que se denuncia, anatomicamente, pelo reduzido volume do órgão, 6, 5, 4 cms., do orifício externo ao fundo, em vez de 7, pelo pequeno diâmetro do colo com orifício externo puntiforme, e canal cervival ocupado por espessa e aderente rolha mucosa, por ante-flexão fortemente angulosa; e, clinicamente, por dismenorréa e esterilidade.

No útero hịpoplásico concorrem múltiplas condições capazes de promover a esterilidade, agindo ora isoladamente, ora associadas. Num caso, é a inferioridade estrutural do endometrio que não the permite de reagir satisfatoriamente ao estímulo hormônico, para atender às exigências da implantação e do crescimento do ovo; num outro, é a espessa rolha mucosa cervical que, ou embaraça, mecanicamente a passagem do espermatozoide, ou hostilisa quimicamente a sua vida. Esclarecidos que fiquemos sobre a ocurrência de uma hipoplasia pelos informes da anamnese, conjugados aos do exame local toque e sondagem do útero - cumpre apurar si há ou não hostilidade da secreção cervical, recorrendo ao chamado test de HuHner. Consiste ele em se retirar secreção do canal cervical, 6 a 8 horas após o coito e por meio de aspiração com pipeta, e verificar, ao microscópio, a porcentagem de espermatozoides vivos existentes e daí inferir a a conclusão. A constatação da hipoplasia satisfaz o nosso objetivo diagnóstico e inspira a conduta terapêutica a ser adotada. $O$ estímulo hormônico peals substâncias estrogenas, é a indicação maxima, sinão o recurso soberano. Submete-se a doente à medicação continuada e intensiva pelos preparados foliculinicos e gonadotrópicos com o que se conseguirá promover sensivel crescimento do útero, melhorar as condições estruturais do mio-endométrio e corrigir a hostilidade do muco cervical. Como providência complementar, pratique-se uma curetagem que reforça o efeito de medicação e retira o eventual em- 
baraço mecânico do muco do colo. Este último detalhe foi encarecido pelo prof. von Tongeren, de Amsterdam, que em recente Congresso, aduziu casos de esterilidade curados, tão somente, pela introdução da sonda cervico-uterina.

\section{CAUSAS TUBÁRAS}

Afastada a responșabilidade uterina pela negatividade do exame local, é numa condição patológica das trompas, mais precisamente, numa obstrução de origem inflamatãria que reside a causa mais frequente da esterilidade feminina. Cerca de $56 \%$ dos casos de esterilidade, subordinam-se a esse mecanismo étio-patogênico. Impõe-se, portanto; em todos os casos perquirir as condições das trompas. Si permeáveis, si obstruidas. Para esse efeito, são de uso corrente dois métodos exploradores: a insuflação transuterina (método de RUBIN) e a salpingografia. Um e outro nos trazem precioso esclarecimento. Enquanto a insuflação apenas afirma a existência da obstrução, a salpingografia positiva a sua séde - si no trajeto intersticial, istmico, ampolar ou infundibular da trompa. Dada a ineficiência do toque neste particular, o emprego desste meio explorador é, não só de regra como imperativo nos casos de esterilidade. Acresce, ainda, que à eficiência diagnóstica essa exploração reune uma valiosa virtude terapêutica - a de constituir o.meio mais hábil de que dispomos para a desobstrução tubária. Tanto mais a ser encarecido, quanto é certo que as perspectivas inherentes aos métodos cirurgicos são pouco anjmadoras, pela precariedade dos resultados até hoje obtidos. Dizem as estatísticas que, das múltiplas técnicas operatórias preconisadas para remover a obstrução tubaria, o exito não foi obtido em mais de $10 \%$ dos casos com prenhez ulterior. De uma tenho conhecimento pessoal, em que se alinham 64 casos operados, com um unico sucesso e esse mesmo de prenhez octopica. Guarde-se, pois, como noção pratica e lição da experiência que, nos casos de obstrução tubaria causadora de esterilidade, o tratamento que melhores chances oferece é a insuflação repetida, recorrendo aos métodos cirurgicos - salpingostomia, resseç̧ão e implantação tubária, salpingectomia seguida de implantação ovariana a "Estes" - quando a insuflação não conduza a êxito, hipotese em que a paciente deverá ser previamente informada, das exíguas possibilidades de sucesso, como condição primordial para - $\mathrm{o}$ ato operatório.

Pode-se dar o caso de estarem as trompas ${ }^{\circ}$ trabalhadas por processo inflamatório que thes preserve a permeabilidade, mas que afecte o seu normal peristaltismo, indispensavel para o êxito da concepção. Mikulics-RAdEki realisou, a respeito, curiosas observações. Por meio de radioscopias, paciente e cuidadosamente conduzidas, durante o ciclo, verificou que, no momento da ovulação e, por meio de movimentos peristálticos adequados a trompa envolve o ovário ovulante num amplexo aconchegado afim de que as franjas do seu pavilhão se 
ajustem mais intimamente à sua superfície, de maneira a garantir a queda do óvulo em suas malhas e consequente migração para a luz tubária. Venha a faltar à trompa, aptidão para realisar esse movimento, e o óvulo, em vez de ser por ela acolhido, perder-se-à na cavidade peritoneal. E a mulher sofrerá de esterilidade de causa tubária, a respeito de subsistir a permeabilidade, situação dificil de ser modificada com os recursos a nosso alcance.

\section{CAUSAS OVARIANAS}

$\mathrm{Na}$ esterilidade de causa ovariana, há três hipóteses a considerar, numa das quais e esterilidade ocurrente terá, necessáriamente, de se enquadrar. 1) não há maturação nem ruptura de folículo; 2) há maturação, sem ruptura folicular; 3) há maturação e ruptura, mas com deficit hormônico. No primeiro caso, trata-se de uma aplasia ovariana. Nem folículo maduro, nem postura ovular, nem corpo amarelo. Ovário inativo e ovário inexistente, são termos que se equivalem. A mulher sofrerá de uma amenorréia primitiva e sua incapacidade para conceber é incuravel e definitiva. Provocar-lhe uma menstruação artificial, está dentro de nossas possibilidades terapêuticas, curá-la, porém, não. No que respeita à amenorréias como expoente da inatividade ovariana, quando secundárias, sua significação e seu prognóstico variam com a sua duração. Assim datando de menos de dois anos em geral reagem bem à terapêutica adequada e são de facil remoção; com mais de dois anos, já as perspectivas favoráveis se reduzem a $1 / 25$; com 5 anos ou mais, a cura é tão improvavel que, praticamente, equivale a $0 \%$ São incuráveis.

$\mathrm{Na}$ segunda hipotese figurada - há maturação do folículo, sem ruptura - consequentemente, não há ovulo, nem formação de corpo amarelo, e a mulher será esteril, enquanto perdurar essa anomalia. Nesses individuos, a aparência clinica é de perfeita normalidade. Nenhum disturbio menstrual denuncia aquela condição patológica. As crises catameniais se sucedem em ritmo rigorosamente fisiológico, quanto à duração e intervalos. O ciclo é, porém, monofásico e o fato foi capitulado de pseudo-menstruação. Essa ocurrência, já conhecida nas macacas, foi constatada, mais recentemente, tambem na mulher, onde se verificaria com relativa frequência, chegando-se mesmo à afirmação de que é fisiológica durante certo período, em seguida à menarca e antes da menopausa. E' a chamada esterilidade funcional, cujo diagnóstico só é possivel, pela curetagem, nos dias que precedem, imediatamente, a menstruação, em que se retira endométrio de, estrutura peculiar à fase proliferativa e não a da premenstrual. Excluidas que sejam quaesquer outras causas esse achado microscópico autoriza concluir pelo ciclo monofásico e, consequente esterilidade. Como terapêtica, cuide-se de promover, artificialmente, a ruptura folicular com formação de corpo amarelo administrando-se à paciente hormônios gonadotrópicos pre-hipofisários, de preferência, talvez, os de ori- 
gem corionica, aos quais a moderna fisiologia atribúe aquela virtude. Essa mesma ausência de ruptura folicular condiciona outra modalidade anátomo-clínica, quando múltiplos folículos amadurecem e não se rompem, mas persistem, de que resultá acúmulo de substância estrogênica, com estímulo exagerado do endométrio, acarretando, sob o ponto de vista anátômico, a hiperplasia glandular cistica, sob o ponto de vista clínico meno e metrorragias eventualmente agravadas por esterilidade. Para o seu diagnóstico aplica-se o que ficou dito para o caso anterior. No $30^{\circ}$ e último item - em que há maturação e ruptura de folículo, mas deficit hormônico - o fato anátomoclínico que defrontamos é o da hipoplasia ou do infantilismo, com o cortejo de sinais que o denunciam e as providências terapêtuticas já explanadas, por ocasião do estudo das causas uterinas e sobre as quais seria ocioso voltar.

Haveria, ainda, dois outros tipos de esterilidade a serem considerados: a de causa extra-genital e a esterilidade sem causa. Não nos detenhamos tm debater a do primeiro tipo. A causa extra-genital atúa indiretamente e sempre através do ovário, onde promove uma disfunção secundária que, em última análise, viria incidir numa das hipóteses já consideradas. Sem causa é a esterilidade dos casais rigorosamente sadios, pelo menos, nos quais os nossos atuais recursos exploradores não conseguem descobrir qualquer anormalidade; casaes, entretanto, cuja capacidade procreadora se patentêia com eloquência, quando cada conjuge, após separação, convola a novas nupcias. E' o que os ingleses chamam "germinal incompatibility". E' um impasse da propedêutica que, até este momento, não foi esclarecido. $\mathrm{O}$ fato tem preocupado o espírito investigador dos scientístas americanos e, a se aceitarem os primeiros resultados de suas pesquizas, parece que a ponta do véu começa a ser levantada. Muito interessantes, a respeito, são os estudos e idéias de MEAKER, de recente publicação. Fundando-se na preliminar de que a aptidão para procrear resulta de um conjunto de fatores, a serem considerados, sempre, no casal, como um todo e nunca em cada conjugue, isoladamente, elle estabelece a noção do "indice de fertilidade" peculiar a cada casal e raciocina: "os elementos que conduzem a um grau normal de fertilidade não são fixos, mas variáveis e sujeitos à influência favoravel ou hostil de fatores múltiplos, por vezes, de valor reduzido, mas em determinadas circunstâncias, de indiscutivel importância. Procedendo-se, em cada indivíduo, a um minucioso estudo médico, endócrino e genital, chegase à fórmula do seu índice de fertilidade que póde ser alto, médio ou baixo. Assim, a esterilidade do casal pode resultar da união de dois indivíduos de "baixo índice", cada um deles, entretanto, apto a terem filhos, quando sei casem, de novo com indivíduo de "índice alto". Em outras palavras a união esteril não decorre de condições existentes num só dos conjuges, mas da soma de fatores múltiplos apreciados em ambos". Sob o ponto de vista prático, diriamos homem de "alto índice de fertilidade" casando-se com mulher de "índice baixo", ou vice-versa, terá filhos; homem e mulher de "baixo 
indice", significará casal esteril; homem de "baixo índice" e mulher de "indice médio", ou vice-versa, procreação possivel mas dificil e espaçada.

Estudada a étio-patogenia da esterilidade com a terapêutica geral aplicavel em cada caso, vejamos, como noção prática a ser retirada desse estudo, qual a conduta clínica a ser seguida, em cada caso de esterilidade que se nos apresente. De começo, capacitemo-nos de que se trata, realmente, de um caso de esterilidade. Dada a diversidade. com que a aptidão para procrear se manifesta, de mulher' a mulher, convencionou-se considerar esteril o casal que não tem filhos, após três anos de vida sexual normal. Antes desse prazo, seria prematuro qualquer tratamento, com exame negativo. Quando procurados, em tais circunstâncias tranquilisemos a consulente, sob esse fundamento. explicando-lhe que apenas $15 \%$ dos casais têm filho durante o primeiro ano de vida conjugal. Constatada a esterilidade tratemos de apurar a possivel resposabilidade do marido. Foi-se o tempo em que as mulheres tinhan de carregar sozinhas; a culpa pela falta de prole. $\mathrm{O}$ orgulho dos homens nunca thes permitiu se conformassem com essa inferioridade fisiológica. A situação hoje é diversa. Pela esterilidade tanto responde o homem como a mulher. Eis porque tornou-se doutrina pacífica.que essa anormalidade deve ser apreciada, sempre, no casal e não isoladamente, num só dos conjuges. Há mesmo quem afirme que num terço dos casos, a responsabilidade é diretamente do marido, em outro terço, indiretamente ainda do marido, pelas moléstias que transmitiu à mulher e só no terço restante, cabe culpa direta e exclusivamente à mulher. Há evidente exagero nessa afirmativa, mas não se afasta da verdade, comprovada pelas statísticas, culpar-se - homem por $40 \%$ dos casos de esterilidade. Reclame-se, pois a presença do marido, proceda-se ao seu interrogatório e exija-lhe exame do esperma, por laboratório idoneo, não nos contentando com a informação que, porventura nos der, de que tal exame já foi feito, com resultado favoravel. Liquidada essa preliminar, passemos a investigar em nossa paciente, a causa ou causas de sua esterilidade. Para esse efeito, cumpre proceder meticuloso exame somático geral e genital, precedido de cuidadosa e completa anamnese, na qual nenhum detalhe ou aspecto mesmo os que dizem com intimidade de sua vida sexual, seja omitido. No exame ginecológo, após inspecção do ventre e dos genitais externos, pratique-se o toque levando a mente orientada para a eventualidade da hipoplasia, causa das mais frequentes, mormente qundo já suspeitada pelos informes da anamnese. Vagina afúnilada, fundos de saco apagados ou quasi, colo pequenos e de reduzido diâmetro, corpo tambem pequeno em forte anteflexão confirmam a suspeita, esclarecem a diagnostico e orientam a terapêtica. Dessa exploração fazem parte integrante, a sondagem do útero e o test de HUHNER, aquela tambem como objetivo de remover o embaraço mecânico constituido pelo muco cervical espesso e aderente, e este visando verificar a possivel hostilidade dessā secreção. Afastada a hipoplasia e negativo o resultado do toque, para as trompas, indaguemos 
da sua permeabilidade, seja pela insuflação, seja pela salpingografia, tendo presente que, a obstrução tubária tem na prpria insuflação, o seu recurso mais eficiente de cura, para o qual, pois, se deverá apelar, antes de aconselhar e submeter a paciente ao tratamento cirurgico, de resultados ainda hoje precários. Casos haverá em que, proposta a operação, como recurso extremo, para corrigir uma obstrução tubária, seja ela aceita pela paciente, sem hesitação. Mas antes de praticá-la, é dever de conciência esclarecer a interessada sobre as fracas perspectivas que of erece.

Excluido o embaraço tubário, restará investigar a causa ovariana. O normal funcionamento do ovário se infere da maneira como decorre o ciclo menstrual. A menstruação é o espelho do ovário. Regras subordinadas ao ritmo fisiológico, na incidência, na duração e na quantidade, presupõem ovários sãos e equilibrio endócrino. Não deve, pois, ter essa origem a esterilidade em apreço. A menos que não ocorra a hipotese da pseudo-menstruação, do ciclo monofásico, atraz, descrito, aliás de facil reconhecimento pela estrutura do endométrio nas yesperas da deflagração menstrual. Umà curetagem, nos dias que precedem a crise, denunciando a mucosa em proliferação, 'confirmaria a hipotese. Teriamos com isso, o diagnóstico firmado e firmada a diretriz terapêtica: promover artificialmente a ruptura do foliculo. Preconisa-se, hoje, como recurso mais idoneo para esse efeito, a administração de hormônios gonadotropicos, de origem corionica contidos no soro sanguineo da égua prenhe. Quando haja disfunção do ovário, por excesso ou deficiência, primitiva ou secundária a disturbios de outra ou outras glândulas, o estudo em conjunto, do aparelho endócrino, com metabolismo basal fornecerá proveitosas indicações.

Este é o caminho a ser trilhado, na clínica. Muito embora, penoso e inçado de dificuldades, é o que a experiência aconselha como o mais apto para conduzir a êxito. E' o que tambem comprova o depoimento das mais recentes estatísticas. Em trabalho americano que há pouco lí, deparei com as seguintes sugestivas cifras:

Em 236 casais estéreis, só com o exame e manobras exploradoras, foi conseguida a prenhez em 27 , ou seja $118 \%$ de êxito.

Em _outros 202 casais, tambem estéreis devidamente.examinados e tratados pela forma exposta, obteve-se prenhez em 132 casos, ou seja $65,3 \%$ de cura. São resultados quasi surpreendentes e que dispensam comentários. $E$ o que fere a atenção:nesses números, é a elevada cifra de sucesso obtida tão somente com manobras expioradoras - sondagem do canal cervical e útero - o que vem emprestar verosimilhança ao conceito de von ToNGEREN, do papel representado pela rolha mucosa cervical na etiologia da esterilidade.

Eis, senhores, condensado nas considerações que venho de aduzir o que se me afigurou de mais interessante e prático scbire este relevante assunto. Não desejo, entretanto, encerrar esta despretenciosa palestra, sem uma advertência amiga. Em matéria de esterilidade feminina é de bom aviso, quanto ao prognóstico, abster-se o médico 
de afirmações absolutas, de sentenças inapeláveis, qualquer que seja a convição a que tiver chegado. Nunca se diga à consulente que ela nada tem e que o desejado filho virá inevitavelmente, assim como, nunca se lhe tire a esperança de ser mãe, afirmando a impossibilidade de vir a conceber. Porque os fatos frequentemente, se encarregarão de vos desmentir e desapontar, com sério prejuizo para o vosso bom nome profissional.

\section{Gengivas doentes?}

\section{"PYOR R H O N"}

Dá sqúde ás gengivas, porque é remédio e... é dentifricio

O departamento de ADMINISTRAÇÃO PREDIAL DA

Caixa Geral de Emprestimos REGULARIZARÁ E AUGMENTARA O RENDIMENTO DOS PREDIOS DE V.S.

IDONEIDADE ABSOLUTA

PRESTAÇÃO RIGOROSA DE CONTAS

CAIXA GERAL DE EMPRESTIMOS

Caisse Générale de Prêts Foncièrs et Industriels

Rua Tabatinguera, 164 - Fone 2-4722 - SÃO PAULO 